\title{
THERMO-ACOUSTICALSTUDIES INTWO-FOLD FLUID BLENDS AT DIFFERENT TEMPERATURES
}

\author{
A. Nagarjuna ${ }^{1}$, Shaik. Babu ${ }^{2, \bowtie}$ and D. Das ${ }^{3}$ \\ ${ }^{1}$ Department of Physics, Andhra Loyola College (Autonomous), Vijayawada, A P, India \\ ${ }^{2}$ Department of Physics, Koneru Lakshmaiah Education Foundation, Vaddeswaram, \\ Guntur, A.P, India \\ ${ }^{3}$ Department of Chemistry, Dinhata College, North Bengal University, Dinhata, Cooch- \\ Behar 736135, West Bengal, India \\ Corresponding Author: drshaikbabu.physics@gmail.com
}

\begin{abstract}
Speed of sound, viscosity and density of a fluid blend of p-Methoxy benzoic acid (p-MBA) with alkanols (1propanol/1-butanol/1-pentanol/1-hexanol) have been examined from $303.15 \mathrm{~K}$ to $313.15 \mathrm{~K}$ ( $5 \mathrm{~K}$ interval) temperature at $2 \mathrm{MHz}$ frequency. Several thermo acoustic properties like isentropic compressibility $\left(\mathrm{K}_{\mathrm{s}}\right)$, molar volume $\left(\mathrm{V}_{\mathrm{m}}\right)$, surface tension $(\gamma)$, specific acoustic impedance $(Z)$ and their excess outcomes were deliberated from these measured data. These excess properties have been fitted to the Redlich-Kister type polynomial equation using the least square method to appraise parameters and standard deviations.

Keywords: Fluid Blend, Speed of Sound, Redlich-Kister type polynomial, Thermo acoustic Properties, p-Methoxy Benzoic Acid.
\end{abstract}

RASĀYAN J. Chem., Vol. 14, No.3, 2021

\section{INTRODUCTION}

Speed of sound of fluids and fluid blends has abundant importance in appraising the prospects of speaks coalition and also utilize in majority of industrial processes originate hypothetical interest in perceiving the nature of auxiliary opus ${ }^{1}$. Thermo-acoustic properties have been worn to perceive various sorts of a coalition of mite packing inhume fragment interactivities and their durability ascendance by the size of pure pieces and the mix. The diverged properties flits a spry bit in appraising the solidness due to particle adaption and expanse to fragment interactivities in the blends through charge transfer interactivity of pMethoxy benzoic acid .It is a cognition enhancer and metabolite of aniracetam. p- Methoxy benzoic acid is phenolic acid, organic motes often erect in anis-seed, a common food spice. Its aliphatic layout commits to the volume diminution of profuse systems. p- MBA molecules are spherical so it intricate in many reactions such as electrophilic \& nucleophilic substitution, oxidation and reduction to form many salts. Alkanols are dominant intermediates in the synthesis of profuse organic chemicals also utilized for perfume industry ${ }^{2,3}$. They emanate the metal alkanolate and $\mathrm{H}$ - gas by retaliating from active metals. They were also utilized for initiation of $\mathrm{H}$ - bonds between - $\mathrm{OH}$ groups with weak proton donor ability and dislocate electron pairs on the oxygen atom of ether. Many researchers carried out acoustic parameters to study the molecular interactivities between fluid blends. ${ }^{4-8}$ The aim of the present paper explicate thermo acoustic studies by the profuse hypothesis of excess properties and also RK-polynomial equation upshots from measured values by obtaining inter/intra molecular interactions among a twofold fluid mix of p-MBA with 1-propanol/1-butanol/1-pentanol/1-hexanol are collated with various theoretical relations at $\mathrm{T}=303.15 \mathrm{~K}$ to $313.15 \mathrm{~K} .{ }^{14,15,18}$

\section{EXPERIMENTAL}

The chemicals utilized in this study are p-MBA with alkanols (1-propanol/ 1-butanol/1-pentanol/1hexanol which are of AR grade obtained from Hi-Media Laboratories Pvt. Ltd, Mumbai India, and Sisco research lab Pvt. Ltd, Mumbai, India with purities of greater than 99\%. p -Methoxy benzoic acid be attainable in powder type and it was soluble in water with the array of $530 \mathrm{mg} / 1 \mathrm{lr}$ at room temperature. 
RASĀYAN $J$. Chem.

Vol. 14 | No. 3 |1885-1891| July - September | 2021

The samples were making just to begin the experiment with the succor of mass disparity and uncertainty in blends concentration.

Table-1: Collation of measured to Literature Values of Densities ( $\rho$ ) Viscosities ( $\eta$ ) and Speed of Sound (U) for Pure Fluids

\begin{tabular}{|c|c|c|c|c|c|c|c|c|c|}
\hline \multirow[t]{2}{*}{ Fluid } & \multirow[t]{2}{*}{ Temp (K) } & \multicolumn{2}{|c|}{$\begin{array}{l}\text { Density }(\rho) \\
\text { Kg.m }{ }^{-3}\end{array}$} & \multicolumn{2}{|c|}{$\begin{array}{l}\text { Viscosity }(\eta) \\
\text { mPa s }\end{array}$} & \multicolumn{2}{|c|}{$\begin{array}{l}\text { Speed of sound(U) } \\
\mathrm{m} \mathrm{s}^{-1}\end{array}$} & \multirow[t]{2}{*}{$\begin{array}{c}\mathrm{C}_{\mathrm{P}} \\
\mathrm{J} \mathrm{K}^{-1} \mathrm{~mol}^{-1}\end{array}$} & \multirow[t]{2}{*}{$\begin{array}{c}\alpha \\
\mathrm{k} \mathrm{K}^{-1}\end{array}$} \\
\hline & & Expt & Litt & Expt & Litt & Expt & Litt & & \\
\hline \multirow{3}{*}{$\begin{array}{l}\text { p-Methoxy } \\
\text { benzoic acid }\end{array}$} & 303.15 & $-\ldots$ & 1.188 & $-\cdots$ & 1.585 & 1559.4 & $-\cdots$ & $204.07^{d}$ & $1.000^{\mathrm{e}}$ \\
\hline & 308.15 & $-\ldots$ & 1.123 & $-\ldots$ & 1.428 & 1539.6 & $-\ldots$ & $205.03^{\mathrm{d}}$ & $1.001^{\mathrm{e}}$ \\
\hline & 313.15 & $-\cdots$ & 1.097 & $-\cdots$ & 1.341 & 1520.2 & $-\cdots$ & $205.00^{d}$ & $1.003^{\mathrm{e}}$ \\
\hline \multirow{3}{*}{ 1-Propanol } & 303.15 & 0.799 & $0.796^{\mathrm{a}}$ & 1.611 & $1.610^{\mathrm{a}}$ & 1181.8 & $1190.2^{\mathrm{a}}$ & $140.21^{\mathrm{d}}$ & $1.237^{\mathrm{e}}$ \\
\hline & 308.15 & 0.794 & $0.793^{\mathrm{a}}$ & 1.460 & $1.461^{\mathrm{a}}$ & 1168.8 & $1171.8^{\mathrm{a}}$ & $146.10^{\mathrm{d}}$ & $1.348^{\mathrm{e}}$ \\
\hline & 313.15 & 0.784 & $0.787^{\mathrm{a}}$ & 1.317 & $1.317^{\mathrm{a}}$ & 1149.8 & $1150.0^{\mathrm{a}}$ & $158.60^{d}$ & $1.409^{\mathrm{e}}$ \\
\hline \multirow{3}{*}{ 1-Butanol } & 303.15 & 0.807 & $0.802^{\mathrm{a}}$ & 2.053 & $2.054^{\mathrm{a}}$ & 1225.4 & $1225.8^{\mathrm{a}}$ & $179.50^{d}$ & $1.228^{\mathrm{e}}$ \\
\hline & 308.15 & 0.794 & $0.794^{\mathrm{a}}$ & 1.902 & $1.903^{\mathrm{a}}$ & 1202.8 & $1201.8^{\mathrm{a}}$ & $181.60^{\mathrm{d}}$ & $1.362^{\mathrm{e}}$ \\
\hline & 313.15 & 0.790 & $0.792^{\mathrm{a}}$ & 1.620 & $1.620^{\mathrm{a}}$ & 1153.8 & $1192.6^{\mathrm{a}}$ & $192.20^{\mathrm{d}}$ & $1.427^{\mathrm{e}}$ \\
\hline \multirow{3}{*}{ 1-Pentanol } & 303.15 & 0.815 & $0.813^{\mathrm{a}}$ & 3.012 & $3.013^{\mathrm{a}}$ & 1245.2 & $1254.9^{\mathrm{a}}$ & $201.70^{d}$ & $1.215^{\mathrm{e}}$ \\
\hline & 308.15 & 0.805 & $0.808^{\mathrm{a}}$ & 2.642 & $2.649^{\mathrm{a}}$ & 1232.8 & $1239.6^{\mathrm{a}}$ & $212.30^{\mathrm{d}}$ & $1.357^{\mathrm{e}}$ \\
\hline & 313.15 & 0.802 & $0.806^{\mathrm{a}}$ & 2.305 & $2.309^{\mathrm{a}}$ & 1223.4 & $1218.0^{\mathrm{a}}$ & $240.60^{d}$ & $1.516^{\mathrm{e}}$ \\
\hline \multirow{3}{*}{ 1-Hexanol } & 303.15 & 0.812 & $0.812^{b}$ & 3.516 & $3.513^{\mathrm{b}}$ & 1286.2 & $1288.0^{\mathrm{b}}$ & $240.65^{d}$ & $0.807^{\mathrm{e}}$ \\
\hline & 308.15 & 0.803 & $0.808^{\mathrm{c}}$ & 3.181 & $3.182^{\mathrm{c}}$ & 1276.8 & $1272.5^{\mathrm{c}}$ & $247.70^{d}$ & $0.818^{\mathrm{e}}$ \\
\hline & 313.15 & 0.802 & $0.805^{b}$ & 2.782 & $2.781^{\mathrm{b}}$ & 1261.4 & $1252.0^{\mathrm{b}}$ & $249.15^{d}$ & $0.837^{\mathrm{e}}$ \\
\hline
\end{tabular}

Standard uncertainties ' $\mathrm{u}$ ' are $\mathrm{u}\left(\mathrm{x}_{1}\right)=0.0001, \mathrm{u}(\rho)=0.01 \mathrm{~kg} \cdot \mathrm{m}^{-3}, \mathrm{u}(\eta)=0.003 \mathrm{mPas}, \mathrm{u}(\mathrm{U})=0.9 \mathrm{~m} \mathrm{~s}^{-1}$

${ }^{\mathrm{a}}$ Reference $[11]^{\mathrm{b}}$ Reference[13] ${ }^{\mathrm{c}}$ Reference $[12]{ }^{\mathrm{d}}$ Reference $[16]{ }^{\mathrm{e}}$ Derived from density data

An interferometer (M-81S, M/s Mittal Enterprises, India) may use to measure the speed of sound at 2 $\mathrm{MHz}$ frequency with an exactness of $\pm 0.1 \mathrm{~m} \mathrm{~s}^{-1}$ for p-Methoxy benzoic acid with alkanols and uncertainty in the speed of sound to be established by $\pm 0.9 \mathrm{~m} \mathrm{~s}^{-1}$. The density of mixtures was measured with standard technique (specific gravity bottle) and uncertainty in density is $\pm 0.01 \mathrm{~kg} \mathrm{~m}^{-3}$. The viscosities were measured with an Ostwald viscometer. The viscometer was calibrated at different temperatures using redistilled water. The uncertainty in viscosity measurement is up to $\pm 0.003 \mathrm{mPas}$. The experimental values were compared with their literature values and noted in table 01 .

\section{RESULTS ANDDISCUSSION}

Figures-1(a-d) reveals the upshots of $\mathrm{K}_{\mathrm{s}}^{\mathrm{E}}$, the inter molecular distance between particles increases due to variation of thermal energy resulting decrease of excess isentropic compressibility $\left(\mathrm{K}_{\mathrm{s}}^{\mathrm{E}}\right)$ in methoxy elements. The thickness of mix increases and speed of sound decreases then negative outcomes of $\mathrm{K}_{\mathrm{s}}^{\mathrm{E}}$ are affirmed by the decreasing with a sore in enchanting of alkanols increasing. This prudent a slower release of interactivity in p-MBA molecules.

Figures-2(a-d) reveals the upshots of $\mathrm{V}_{\mathrm{m}}^{\mathrm{E}}$, the excitation energy of p-MBA increases with the rise of thermal energy and hence molar volume decreases. Negative outcomes of $\mathrm{V}_{\mathrm{m}}{ }^{\mathrm{E}}$ due to decreases of the force of cohesion in - $\mathrm{OH}$ fragments in alkanols arises molecular attraction in the mix. It is also discerned that at a stable temperature the captivation of p-MBA velocity increases which transpire the structural changes also rise of inter molecular forces in the mixture. ${ }^{9,10}$

Figures-3(a-d) reveals the upshots of $\gamma^{\mathrm{E}}$, the captivation of p-MBA increases thenthe attenuation coefficient of alkanols increases when the wave is more and more attenuated. The congregation of alkanols is low then $\left(\gamma^{\mathrm{E}}\right)$ are positive and gradually decreases with an increase in the concentration of $p$ MBA. When increases in temperature excess values of surface tension are positive it indicates weak 1886 
RASĀYAN J. Chem.

Vol. 14 | No. 3 |1885-1891| July - September | 2021

interactivity between mites. The upshots of $\mathrm{V}_{\mathrm{m}}{ }^{\mathrm{E}}$ and $\gamma^{\mathrm{E}}$ are confining the fact that both are converse in nature.
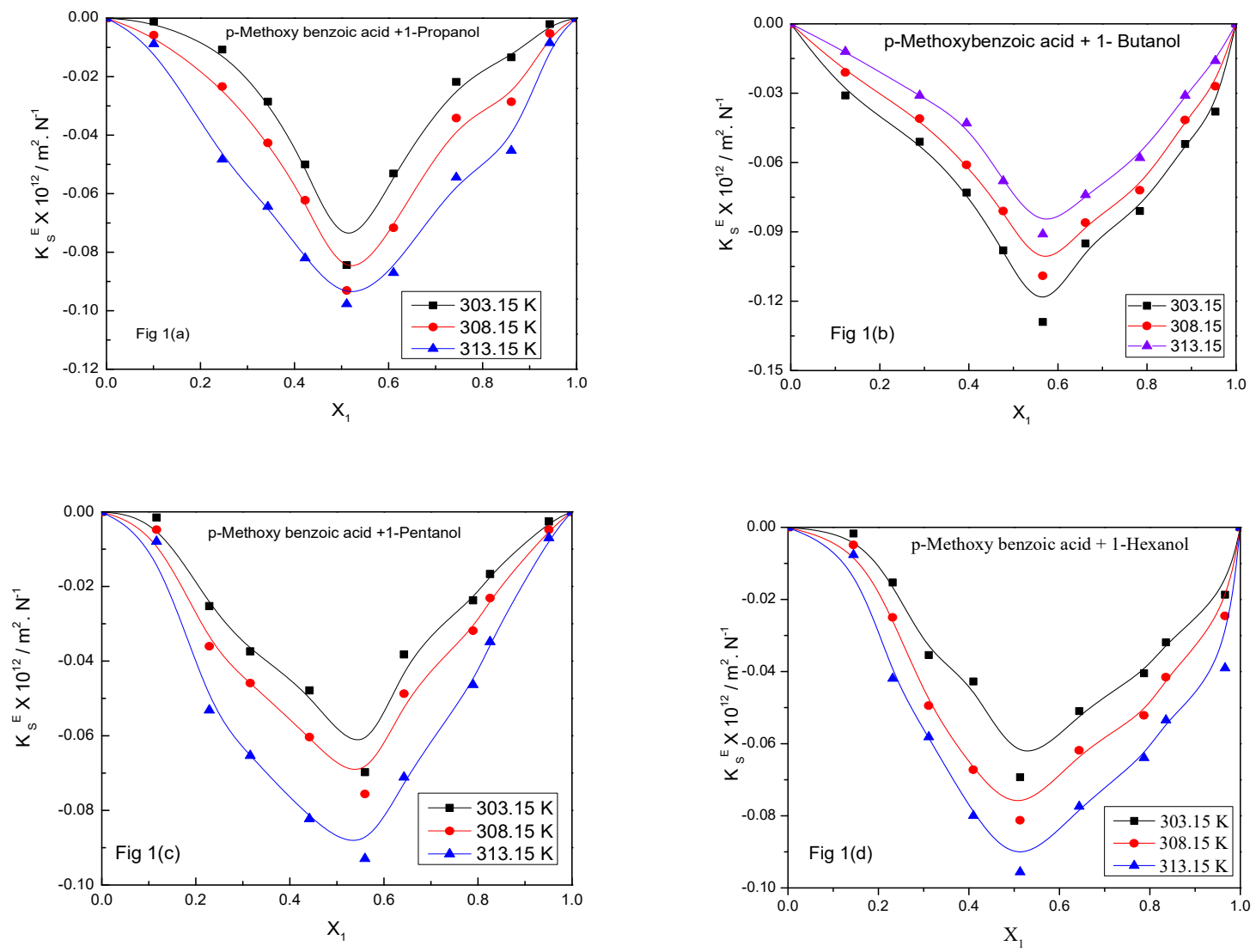

Fig.-1(a-d): Excess Isentropic Compressibility of p-Methoxy Benzoic Acid with 1-Propanol/1-Butanol/1-Pentanol/1Hexanol at Different Temperatures

Figures-4(a-d) reveals the results of $Z^{E}$ in two-fold/ternary fluid blends are utilized to appraise the absorption of sound in the medium. Alteration in the $Z^{\mathrm{E}}$ evaluates discern of spatial variation in the less intensity span of ultrasonic wave the excess acoustic impedance $\left(\mathrm{Z}^{\mathrm{E}}\right)$ becomes less and the values are negative. Also suggests with an increase of temperature decreases in enthrallment of p-MBA indicating that inter molecular interactivity betwixt jots will be weaker and weaker. ${ }^{13,17}$
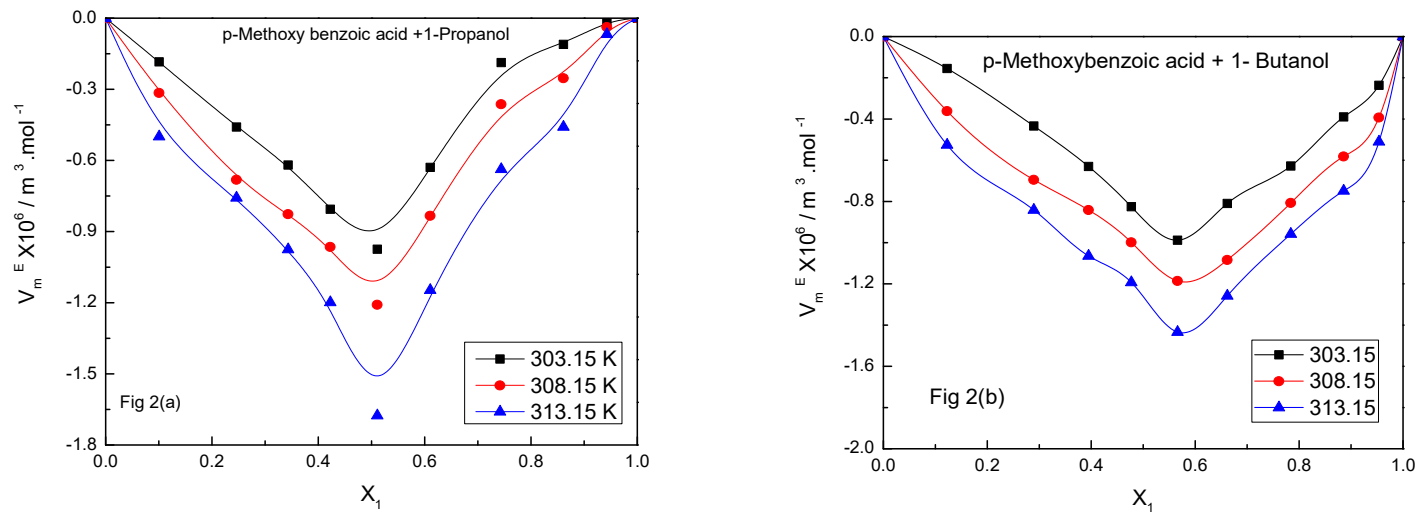

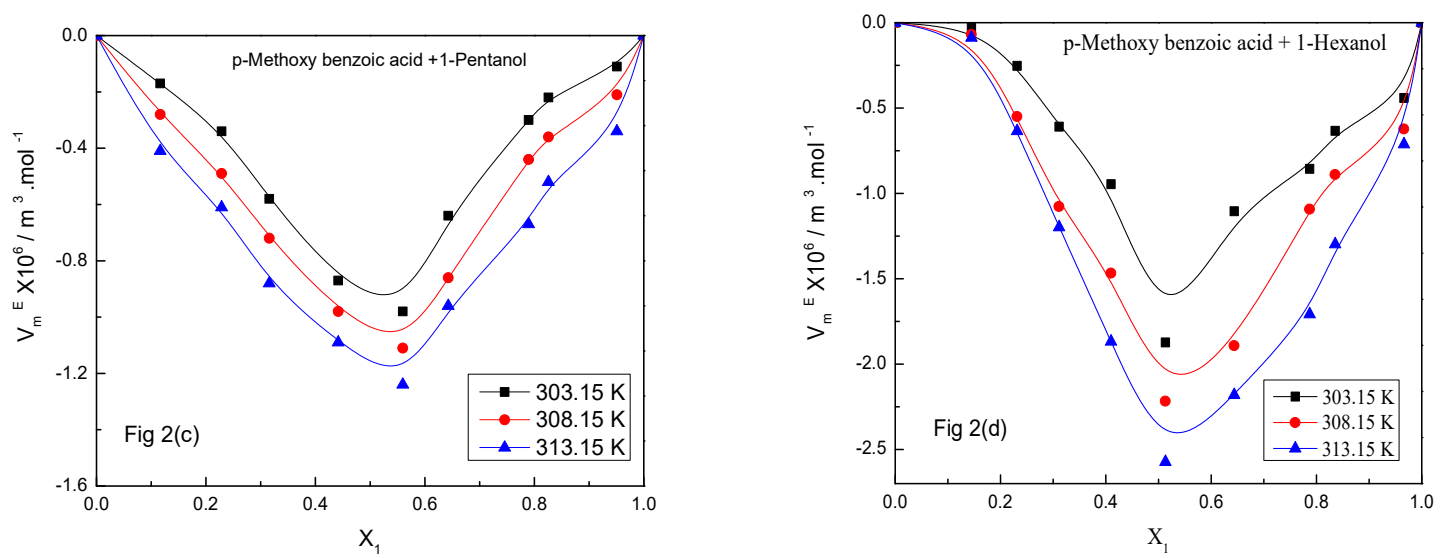

Fig.-2(a-d): Excess Molar Volume of p-Methoxy Benzoic Acid with 1-Propanol/1-Butanol/1-Pentanol/1-Hexanol at

\section{R-K Polynomial} three Different Temperatures

The deviated values of $\mathrm{p}-\mathrm{MBA}$ systems were correlated with R-K equation ${ }^{14}$ at three different temperatures $303.15 \mathrm{~K}, 308.15 \mathrm{~K}$ and $313.15 \mathrm{~K}$.

Table-2 divulge the fitness of mix is debated from acquiring $\mathrm{A}_{\mathrm{k}}$ and standard deviations for Redlich and Kister $\left(\mathrm{Y}^{\mathrm{E}}=\mathrm{V}_{\mathrm{m}}^{\mathrm{E}}, \mathrm{K}_{\mathrm{s}}^{\mathrm{E}}\right.$ and $\left.\gamma^{\mathrm{E}}\right)$ upshots for the system. The pouncing of up comes not only flaunts the viability of blends but also anticipates the rising of digression/ atomic segregation. The standard deviations are satisfactorily obtained it stipulates the snap of $\mathrm{H}$ - bonds in the motes due to emerging of cohesive forces. $^{12,15}$
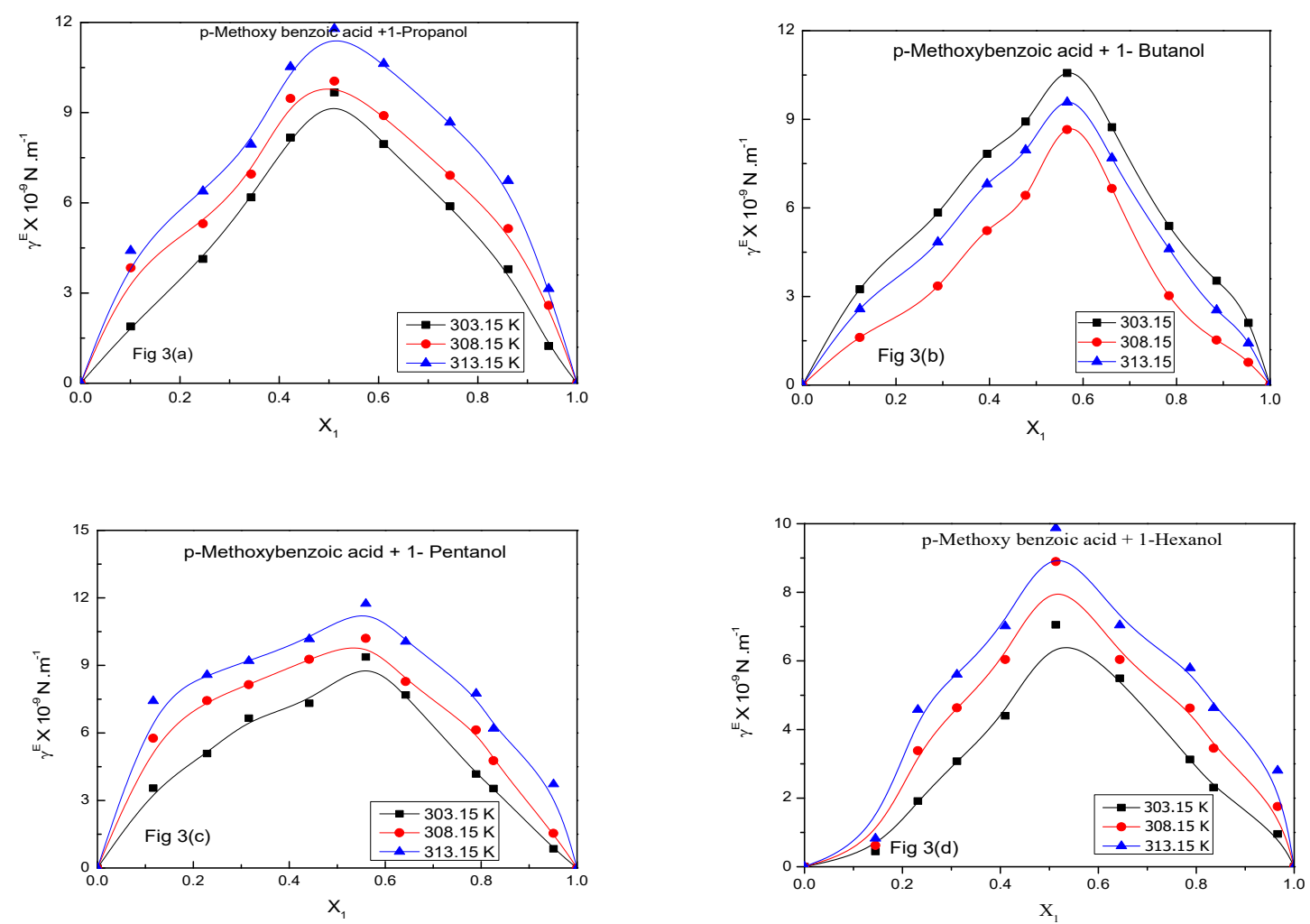

Fig.-3(a-d): Excess Surface Tension of p-Methoxy benzoic acid with 1-Propanol/1-Butanol/1-Pentanol/1-Hexanol at three Different Temperatures 
RASĀYAN J. Chem.

Vol. 14 | No. 3 |1885-1891| July - September | 2021
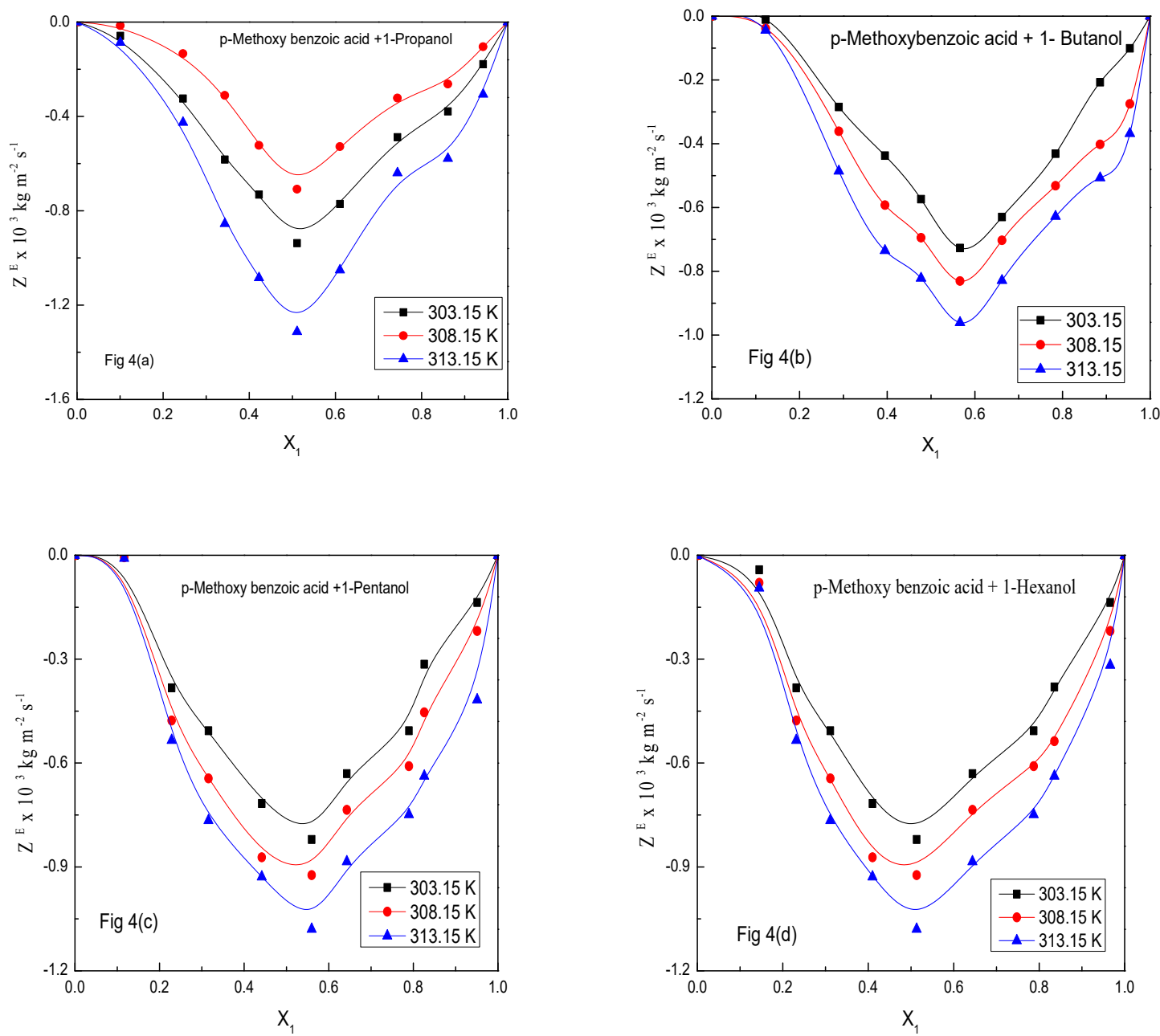

Fig.-4(a-d): Excess Acoustic Impedance of p-Methoxy benzoic acid with 1-Propanol/1-Butanol/1-Pentanol/1-

Hexanol at three Different Temperatures

Table-2: R-K Polynomial Parameters $\left(\mathrm{A}_{\mathrm{k}}\right)$ and Standard Deviation $(\sigma)$ for p-Methoxy benzoic acid + alkanols at $\mathrm{T}=$ $303.15 \mathrm{~K}, 308.15 \mathrm{~K}$ and $313.15 \mathrm{~K}$

\begin{tabular}{c|c|c|c|c|c}
\hline Parameter & Temperature $(\mathrm{K})$ & $\mathrm{A}_{1}$ & $\mathrm{~A}_{2}$ & $\mathrm{~A}_{3}$ & $\sigma$ \\
\hline \multicolumn{5}{c}{$\mathrm{p}-$-Methoxy benzoic acid+ 1-Propanol } \\
\hline \multirow{3}{*}{$10^{12} \mathrm{~K}_{\mathrm{S}}{ }^{\mathrm{E}} /\left(\mathrm{m}^{2} . \mathrm{N}^{-}\right.$} & 303.15 & -0.2261 & 0.5568 & 3.9849 & 0.1135 \\
\cline { 2 - 6 } & 308.15 & -0.2827 & -0.1231 & 0.3656 & 0.0092 \\
\cline { 2 - 6 } & 313.15 & -0.3568 & -0.1346 & 0.3423 & 0.0058 \\
\hline \multirow{3}{*}{$10^{6} \mathrm{~V}_{\mathrm{m}}{ }^{\mathrm{E}}$} & 303.15 & -3.1189 & 0.5568 & 3.9849 & 0.1135 \\
\cline { 2 - 6 }$/\left(\mathrm{m}^{3} . \mathrm{mol}^{-1}\right)$ & 308.15 & -3.9807 & 0.6994 & 3.7063 & 0.1234 \\
\cline { 2 - 6 } $10^{-9} \gamma^{\mathrm{E}} /\left(\mathrm{N}-\mathrm{m}^{-1}\right)$ & 313.15 & -5.1653 & 0.2528 & 3.8522 & 0.1542 \\
\cline { 2 - 6 } & 303.15 & 33.7665 & 10.4235 & -25.4134 & 0.5543 \\
\cline { 2 - 6 } & 308.15 & 35.8859 & 8.4657 & -1.3575 & 0.0663 \\
\hline \multirow{3}{*}{$10^{12} \mathrm{~K}_{\mathrm{S}}{ }^{\mathrm{E}} /\left(\mathrm{m}^{2} . \mathrm{N}^{-}\right.$} & 313.15 & 41.8417 & 12.9645 & 1.6822 & 0.6840 \\
\cline { 2 - 6 } & 303.15 & -2.5035 & -1.4080 & 2.6677 & 0.0307 \\
\cline { 2 - 6 } & 308.15 & -2.788 & -2.255 & 0.680 & 0.055 \\
\hline
\end{tabular}


RASĀYAN J. Chem.

Vol. 14 | No. 3 |1885-1891| July - September | 2021

\begin{tabular}{|c|c|c|c|c|c|}
\hline \multirow{2}{*}{$\begin{array}{c}10^{6} \mathrm{~V}_{\mathrm{m}}^{\mathrm{E}} \\
/\left(\mathrm{m}^{3} \cdot \mathrm{mol}^{-1}\right)\end{array}$} & 308.15 & -2.5035 & -1.4080 & 1.1893 & 0.0486 \\
\hline & 313.15 & -1.4891 & -0.9349 & -13.3124 & 0.7817 \\
\hline \multirow{3}{*}{$10^{-9} \gamma^{\mathrm{E}} /\left(\mathrm{N}-\mathrm{m}^{-1}\right)$} & 303.15 & 36.5229 & 4.9217 & -11.6947 & 0.6095 \\
\hline & 308.15 & 27.6204 & 4.3478 & -27.0134 & 0.7502 \\
\hline & 313.15 & 32.8307 & 3.9953 & -18.8907 & 0.5822 \\
\hline \multicolumn{6}{|c|}{ p-Methoxy benzoic acid+1-Pentanol } \\
\hline \multirow{3}{*}{$\begin{array}{c}10^{12} \mathrm{~K}_{\mathrm{S}}^{\mathrm{E}} /\left(\mathrm{m}^{2} \cdot \mathrm{N}^{-}\right. \\
1)\end{array}$} & 303.15 & -0.2148 & -0.0637 & 0.3190 & 0.0055 \\
\hline & 308.15 & -10.8352 & 0.0364 & 6.6254 & 0.1563 \\
\hline & 313.15 & 0.3463 & -0.0896 & 0.3880 & 0.0037 \\
\hline \multirow{3}{*}{$\begin{array}{c}10^{6} \mathrm{~V}_{\mathrm{m}}^{\mathrm{E}} \\
/\left(\mathrm{m}^{3} \cdot \mathrm{mol}^{-1}\right)\end{array}$} & 303.15 & -3.2171 & -0.5452 & 3.7652 & 0.1072 \\
\hline & 308.15 & -3.7694 & -0.7339 & 2.7251 & 0.1221 \\
\hline & 313.15 & -402173 & -0.9790 & 1.0340 & 0.1407 \\
\hline \multirow{3}{*}{$10^{-9} \gamma^{\mathrm{E}} /\left(\mathrm{N}-\mathrm{m}^{-1}\right)$} & 303.15 & 32.5558 & 0.3914 & -18.0808 & 0.6745 \\
\hline & 308.15 & 37.6421 & -5.1806 & -0.1652 & 0.5076 \\
\hline & 313.15 & 41.0641 & -2.0253 & 24.3967 & 0.6774 \\
\hline \multicolumn{6}{|c|}{ p-Methoxy benzoic acid+1-Hexanol } \\
\hline \multirow{3}{*}{$\begin{array}{c}10^{12} \mathrm{~K}_{\mathrm{S}}^{\mathrm{E}} /\left(\mathrm{m}^{2} \cdot \mathrm{N}^{-}\right. \\
1)\end{array}$} & 303.15 & -5.0428 & -4.1152 & 4.5158 & 0.2001 \\
\hline & 308.15 & -7.2290 & -5.1098 & 5.8107 & 0.1718 \\
\hline & 313.15 & -8.6911 & -7.0733 & 5.8150 & 0.1396 \\
\hline \multirow{3}{*}{$\begin{array}{c}10^{6} \mathrm{~V}_{\mathrm{m}}^{\mathrm{E}} \\
/\left(\mathrm{m}^{3} \cdot \mathrm{mol}^{-1}\right)\end{array}$} & 303.15 & -0.2178 & -0.1697 & 0.1479 & 0.0213 \\
\hline & 308.15 & -0.2824 & -0.1882 & 4.5158 & 0.0231 \\
\hline & 313.15 & -0.3291 & -0.2291 & 0.0532 & 0.0278 \\
\hline \multirow{3}{*}{$10^{-9} \gamma^{\mathrm{E}} /\left(\mathrm{N}-\mathrm{m}^{-1}\right)$} & 303.15 & 22.8646 & 11.7635 & -25.8255 & 0.4520 \\
\hline & 308.15 & 28.8243 & 14.0261 & -22.5555 & 0.6235 \\
\hline & 313.15 & 32.4061 & 17.5566 & -13.5130 & 0.8002 \\
\hline
\end{tabular}

CONCLUSION

The measured values for p-methoxy benzoic acid with alkanols were procured using standard techniques and the obtained data were compared with literature. The deviations of p-MBA with alkanols have positive /negative values given by $\mathrm{V}_{\mathrm{m}}^{\mathrm{E}}, \mathrm{K}_{\mathrm{s}}^{\mathrm{E}}, \gamma^{\mathrm{E}}$ and $\mathrm{Z}^{\mathrm{E}}$ at the whole concentration range due to monomers in the binary system also impulse of charge distortion elements dominates inter molecular association between these systems. Since the p-MBA particles are spherical, then the preferment of temperature in $\mathrm{OH}$ molecules eases an agitation in thermal energy ensue the detachment of piece forms the digressions in coefficients of R-K equation of this liquid mix.

\section{ACKNOWLEDGMENT}

Author (A. Nagarjuna) is thankful to his guide Dr. Shaik Babu, Asst. Professor, Department of physics (DST-FIST sponsored department), K L E F, Guntur, A.P for his valuable suggestions.

\section{REFERENCES}

1. S. M. Ibrahim, F. Mabood, K. Suneetha and G. Lorenzini, Jounal of Engineering Thermalphysics, 26(2), 234(2017), https://doi.org/10.1134/S1810232817020084

2. A.S.G. Prasad,T.B. Rao,D. Rambabu,M.V.B. Rao and M.Pal, Mini-Reviews in Medical Chemistry, 18(10), 895 (2018), https://doi.org/10.2174/1389557517666170412112619

3. B. Chaithanya, I.V. Kasiviswanath and D. C. Prabhakar, Bulletin of the Chemical Society of Ethiopia,33(2), 321(2019), https://doi.org/10.4314/bcse.v33i2.12

4. K. J. Reddy, M. N. Reddy and K. Ramakrishna, Journal of Physics: Conference Series, 1344(1),012022(2019), https://doi.org/10.1088/1742-6596/1344/1/012022

5. P.Suresh kumar and G.V. Krishna Mohan , Rasayan Journal of Chemistry, 11(4), 1696(2018), http://dx.doi.org/10.31788/RJC.2018.1144093

6. U.Nagababu, B.Govind, B.S. Diwakar and A.Chatterjee, International Journal of Scientific and TechnologyResearch, 8(11), 1411(2019)

7. S.K Subhani,B.Suresh and V.S Ghali, Infrared Physics and Technology, 88, 41(2018), https://doi.org/10.1016/j.infrared.2017.10.009 
RASĀYAN J. Chem.

Vol. 14 | No. 3 |1885-1891| July - September | 2021

8. K.V. Chandrasekhar and N. Manjula, International Journal of Mechanical Production Engineering Research and Development, 8(1), 353(2018), https://doi.org/10.24247/ijmperdfeb2018039

9. M. Gowrisankar, A.Venkatesulu,T. Srinivasa Krishna and K Ravindhranath, Journal of Chemical Thermodynamics, 107,104(2017), https://doi.org/10.1016/j.jct.2016.12.019

10. P. Suneetha, T.S.Krishna, M. Gowrisankar, K. Ravindhranath and D Ramchandran, Journal of Chemical Thermodynamics, 108, 181(2017), https://doi.org/10.1016/j.jct.2017.01.014

11. A. Nagarjuna and Shaik Babu, Chemical Data Collections, 26, 100347 (2020), https://doi.org/10.1016/j.cdc.2020.100347

12. L.Venkatramana, K. Sreenivasulu and K. Siva Kumar, Journal of Thermal Analysis and Calorimetry, 115, 1829(2014), https://doi.org/10.1007/s10973-013-3473-9

13. S.S. Sastry, S. Babu, T.Vishwam, K. Parvateesam and H.S. Tiong, Physica. B Condensed.Matter, 420,40 (2013), https://doi.org/10.1016/j.physb.2013.03.028

14. O. Redlich and A.T. Kister, Industrial and Engineering Chemistry, 40, 345(1948), https://doi.org/10.1021/ie50458a036

15. A. Nagarjuna, K.V.Yamini Kanth, G. Balaji Prakash and D. Das, Rasayan Journal of Chemistry,12(4), 1774 (2019), http://dx.doi.org/10.31788/RJC.2019.1245469

16. R.C. Reid J.M. Prausnitz and B.E Poling, The Properties of Gases and Liquids, $5^{\text {th }}$ ed., (MGH Book Company, New York), 1987, https://doi.org/10.1036/0070116822

17. S. K. Suriya Shihab, K. Govinda Rao, M. Gnana Kiran, S. Babu and S.S Sastry, Rasayan Journal of Chemistry, 10(1), 59 (2017), https://doi.org/10.7324/RJC.2017.1011552

18. T. Kalimulla, D. Das, M. Gowri Sankar, K. Govinda Rao and Shaik Babu, Rasayan Journal of Chemistry, 12(4), 1909(2019), http://dx.doi.org/10.31788/RJC.2019.1245481

[RJC-6211/2020] 